\title{
PERANCANGAN SISTEM APLIKASI REQUEST MAINTENANCE TEKNIK DI PERGURUAN TINGGI RAHARJA
}

\author{
Al Husain ${ }^{1}$ \\ Jaka Prima Maulana \\ Yuli Widiastuti ${ }^{3}$
}

Dosen STMIK Raharja ${ }^{1}$, Alummi STMIK Raharja ${ }^{2}$, Mahasiswa STMIK Raharja ${ }^{3}$. Alamat : Jl. Jendral Sudirman No.40, Modernland, Tanggerang ${ }^{1,2,3}$

E-mail : alhusain@raharja.info', jaka.prima@raharja.info ${ }^{2}$,yuli.widiastuti@ raharja.info ${ }^{3}$

\begin{abstract}
ABSTRAK
Perkembangan teknologi informasi yang semakin cepat, membuat sistem berubah dan berkembang sampai kebutuhan akan informasi yang diinginkan dapat diakses dengan mudah dan akurat. Begitu juga dengan operasional Perguruan Tinggi Raharja yang menginginkan kehandalan sebuah sistem. Dalam hal tersebut operasional pengadaan barang kebutuhan dan perbaikan pada Perguruan Tinggi Raharja sampai saat ini dilakukan oleh staff teknik dengan langsung mengerjakan permintaan melalui telvon atau berbicara secara langsung, sehingga kurang memadai sebagai pengingat task request perbaikan dan pengadaan laporan aktifitas Staff. Hal tersebut menciptakan pemberlakuan sistem pengadaan laporan aktifitas maintenance teknik yang direalisasikan dengan penggunaan media kertas sebagai media pengajuan staff. Namun gagasan metode sistem tersebut memiliki kelemahan yang memperlambat kinerja dalam pembuatan laporan. Dari hal tersebut dilakukannya penelitian yang bermetodekan pengumpulan data sistem berjalan, observasi, wawancara dan analisa sistem usulan CSF, metode prototipe dan testing sebagai pembentukan sistem usulan yang memadai sebagai alternative solusi terbaik dari permasalahan yang ada.
\end{abstract}

Kata kunci : Koperasi, Sistem, Aplikasi, Data, Laporan.

\section{ABSTRACT}

The development of information technology is growing rapidly, making the system change and develop until the need for the desired information can be accessed easily and accurately. Likewise with the operational Higher Education Prog who want the reliability of a system. In the case of operational procurement needs and improvements in Higher Education Prog until now carried out by the technical staff directly working on demand through telvon or speak directly, so inadequate as a reminder of the task request repairs and procurement activity reports Staff. It creates the application of the procurement system maintenance activity reports technique realized with the use of paper media as the media filing staff. But the idea of the system method has the disadvantage that slows performance in making the report. From it does research bermetodekan data collection system is running, observation, interviews and analysis of the proposed system CSF, prototyping and testing methods as the establishment of the proposed system is adequate as the best alternative solution of the existing problems.

Keywords: Cooperative, System, Application, Data, Reports

Vol 3 No 1 - Februari 2017 


\section{PENDAHULUAN}

Di era informasi ini kebutuhan akan adanya informasi sangat begitu penting dan mendesak, selain itu unsure g kecepatan, ketepatan, dan keakuratan sampainya informasi sangat diperhitungkan sehingga rantai proses kegiatan yang membutuhkan informasi tersebut dapat dengan maksimal dikerjakan, maka pada Perguruan Tinggi Raharja sebagai penyelenggara pendidikan tinggi yang menitik beratkan pada penggunaan media sarana teknologi komputer terus berinovasi mengembangkan penyediaan sistem komputerisasi yang efektif dan mengefesiensikan pekerjaan tersebut terutama dalam hal pelayanan pendidikan.

Dalam pelayanan pendidikan Perguruan Tinggi Raharja menggunakan kertas dan komputer sebagai media proses bisnisnya, tentu memiliki sistem yang yang berjalan sebagai proses kerja dalam kegiatan, Seperti melakukan pengadaan dan perbaikan terhadap komputer, printer dan jaringan yang terdapat pada staff pegawai demi kelancaran proses kegiatan kerja.

Hingga saat ini proses perbaikan fasilitas-fasilitas computer masih dilakukan secara lisan dengan langsung melakukan permintaan melalui telfon atau berbicara secara langsung kepada anggota staff teknik yang bertugas. Sehingga dikarena banyaknya pemohonan perbaikan (requetst) yang menyebabkan keterlambatan, terlupakan pengerjaan suatu perbaikan terhadap suatu masalah yang terjadi, disebabkan tidak adanya sistem yang memadai sebagai pengingat (task request) perbaikan. kontrol pengawasan atasan terhadap Staff teknik dan pengadaan laporan aktifitas Staff belum terealisasikan dengan baik.

Manajemen operasi teknik yang tidak memiliki laporan aktitas memiliki celah penurunan kinerja SDM teknisi, Penerapan sistem usulan saat ini juga masih juga bersifat manual dengan penggunaan kertas sebagai media validasi perbaikan kerusakan, maka proses entri dan validasi lebih mengganggu pekerjaan utama pegawai staff dengan menyerahkan data permintaan perbaikan tersebut, pegawai staff juga tidak dapat mengetahui kapan perbaikan akan dikerjakan setelah proses request dilakukan. yang akhirnya dapat mempengaruhi proses kerja internal pegawai Perguruan Tinggi Raharja.

\section{PERUMUSAN MASALAH}

Adapun masalah yang dihadapi berdasarkan pengamatan / observasi dari sistem yang sedang berjalan saat ini dalam hal pemberian tugas (task request) pada Perguruan Tinggi Raharja penulis berhasil mengidentifikasikan dan membagi permasalahan menjadi sebagai berikut:

1. Bagaimanakah sistem permintaan perbaikan komputer dan printer yang sedang berjalan pada Perguruan Tinggi Raharja?

2. Apakah penggunaan basis web dalam melakukan request perbaikan menghasilkan pendataan yang lebih mempermudah pengerjaan dan memonitoring penyelesaian tugas?

3. Bagaimana membuat sistem yang user friendly dan simple process dari perancangan sistem web yang akan dibuat?

\section{LITERATUR REVIEW}

Sebagai salah satu upaya yang perlu dilakukan dalam penelitian untuk mengidentifikasi kesenjangan (identify gaps), menghindari pengulangan pembuatan (reinventing the wheel), mengidentifikasikan metode yang pernah dilakukan, serta mengetahui penerapan metode yang dilakukan orang lain dalam area penelitian yang mendekati bidang yang sama dengan penelitian ini, Maka berikut enam penelitian yang memiliki korelasi searah dengan penelitian yang akan dibahas: 
1. Penelitian yang dilakukan oleh Zannuba Rifqi (2014) dengan judul "Efek Infrastruktur Sistem Informasi Dan Perbaikan Proses Terhadap Kinerja Waktu Rantai Pasokan“ penelitian ini dilakukan untuk meneliti perbaikan proses terhadap kinerja waktu rantai pasok, dilakukan dengan menggunakan metode pengumpulan data melalui kuesioner pada metode ini Adalah metode yang dilakukan peneliti untuk mengumpulkan data dan mendapatkan hal-hal yang diperlukan untuk proses penelitian lalu melakukan uji validitas mengukur sah atau tidaknya suatu kuesioner. Lalu menguji reliabilitas untuk mengetahui kehandalan dari suatu alat ukur (kuesioner) dalam mengukur varibel Pengujian reliabilitas akan dilakukan dengan menggunakan Coefficient Cronbach's Alpha yang bertujuan untuk menunjukkan sejauh mana hasil suatu pengukuran dapat diulangi dua kali atau lebih. Kelebihan

2. Dalam jurnal penelitian yang dilakukan oleh Hotmauli Sembiring dengan judul "Perancangan Sistem Informasi Helpdesk pada PT.PINDAD Bandung" pada tahun 2012. Penelitian tersebut ditujukan untuk membantu karyawan dalam hal pengaduan tentang masalah pada software dan hardware yang digunakan diruangannya yang mengalami gangguan atau mempunyai permintaan update software terbaru agar dapat ditindak lanjuti secara cepat dan tepat oleh Staff IT dikantor tersebut. Kekurangan jurnal ini adalah belum adanya report request dari Staff IT. Metode clustering dalam jurnal ini hanya mengelompokkan data dalam pengaduan masalah software dan hardware tanpa adanya permintaan terhadap software dan hardware

3. Menurut jurnal yang dipublikasikan oleh Ancah Nugraha (2011), dengan judul "Aplikasi Helpdesk di CV. Global Mediatama Berbasis Web", Helpdesk merupakan bagian dari perusahaan yang menyediakan dokumen fungsi produk, service atau teknologi dari perusahaan tersebut, kekurangan dalam jurnal ini adalah belum adanya estimasi waktu untuk proses perbaikan software dan hardware. Pengelompokkan data atau clustering dalam jurnal ini terdapat pada pengelompokkan user yang mempunyai akses dalam sistem ini.

4. Penelitian yang dilakukan oleh Ana Nurmaliana dengan judul "PENGEMBANGAN SISTEM INFORMASI CAMPUS SERVICE IDUHELP! PADA PERGURUAN TINGGI RAHARJA" pada tahun 2013. sebuah sistem pelayanan yang terdiri dari dua kegiatan yaitu chat online dan chat offline. Dimana chat online dilakukan secara langsung antara mahasiswa dengan operator yang sedang bertugas saat itu. metode penelitian yang digunakan yaitu dengan metode mengumpulkan dan menggambarkan data mengenai keadaan sistem yang berjalan menjadi objek penelitian untuk mendapatkan data secara relevan. Kelebihan penelitian ini yaitu sistem yang diusulkan dapat berkomunikasi secara langsung, namun memiliki kelemahan tanpa adanya sistem historis informasi hasil obrolan tersebut untuk pengguna.

5. Penelitian yang dilakukan oleh Citra Destianty dengan judul " Pengembangan ROOSTER Dalam Menunjang Sistem Pelayanan iDuHelp! Pada Perguruan Tinggi Raharja” pada 2014. Penelitian tersebut meneliti mengenai pengembangan sistem pelayanan informasi dengan menggunakan ticket online yang akan diberikan kepada pihak terkait, agar dapat memberikan informasi yang akurat. metode pengumpulan data yang relevan diantaranya yaitu metode observasi, metode survei dengan menggunakan iLearning Survey, dan metode studi pustaka yang digunakan. Kelemahannya tidak adanya perbedaan antara tiket yang tertanggani tepat waktu dengan tiket yang terlambat ditanggani.

6. Penelitian yang dilakukan oleh Desintha Ratna Wardani dengan judul "Analisis Dan Perancangan Helpdesk Management System Deposit Library Universitas Gunadarma 
Menggunakan Framework Codeigniter" pada tahun 2009. Penelitian ini meneliti permasalahan pertanyaan dan saran yang ditujukan bagi perpustakaan untuk mengembangkan sistem yang saat ini telah berjalan. Cara yang digunakan untuk menampung keluhan, saran, dan pertanyaan masih kurang efektif, maka dibuat helpdesk yang diharapkan bisa menangani masalah yang ada dengan skala yang lebih besar. Metode yang digunakan dalam penelitian adalah metode SDLC (System Development Life Cycle). Kelebihan penelitian ini yaitu sistem usulan yang dibuat sudah menggunakan framework yang memudahkan untuk kelanjutan pengembangan sistem tersebut, sedangkan kelemahannya yaitu Masih banyak kelonggaran dalam hal coding, misalnya bebas dalam menambah file, Tidak mencerminkan MVC yang sesungguhnya, misalnya penulisan echo masih dapat dilakukan pada file controller.

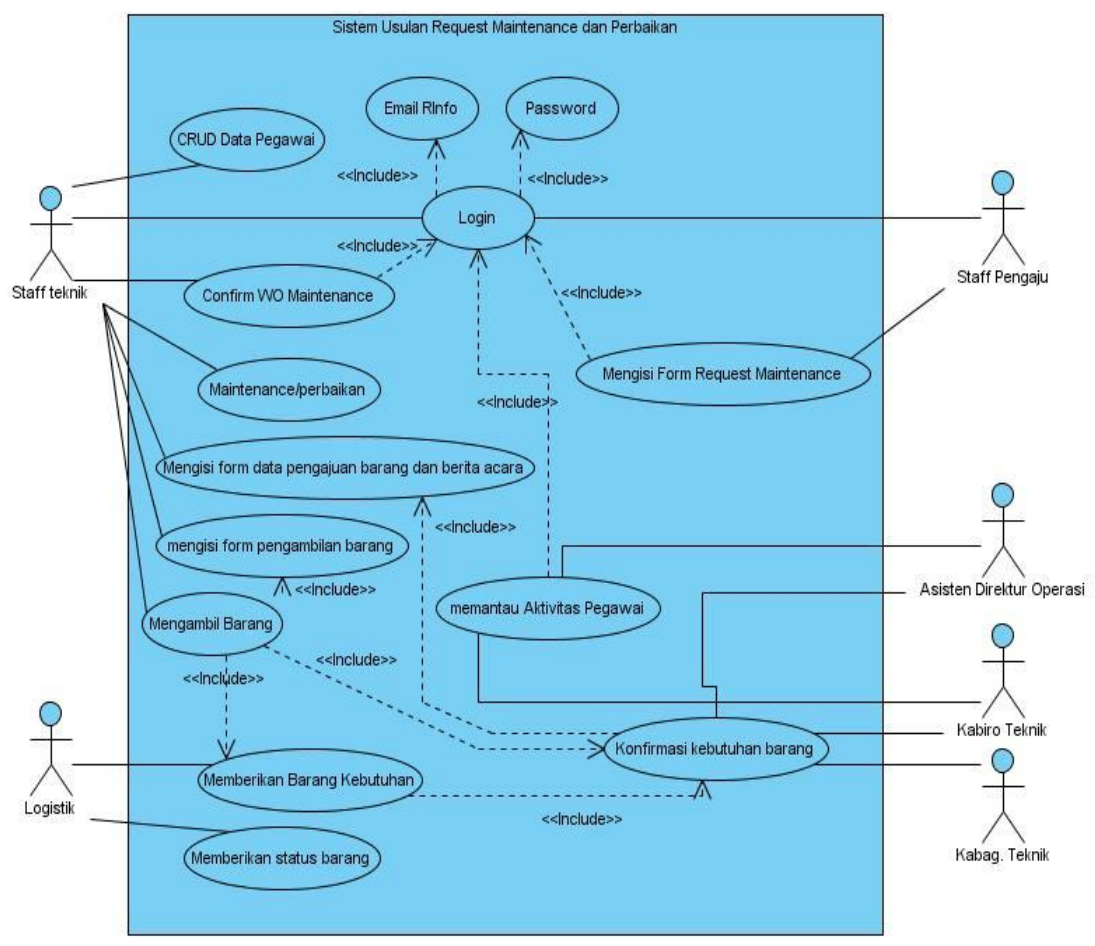

Gambar 1. Use Case Diagram

\section{METODE PENELITIAN}

Metode penelitian yang digunakan dalam peneltian ini adalah metode deskriptif yang merupakan penelitian yang berusaha menggambarkan secara sistematis fakta dan karakteristik objek atau subjek yang diteliti secara tepat.

\section{DESIGN SISTEM}

\section{Use Case Diagram}

Diagram use case digunakan untuk memperlihatkan hubungan-hubungan yang terjadi antara aktor-aktor dengan use case yang ada dalam system sehingga calon pengguna system mendapatkan pemahaman tentang system yang dikembangkan. 
Pada gambar use case diagram diatas, terdapat 5 aktor yaitu : Staff teknik, staff pengaju, logistik, asisten direktur, kabiro teknik, kabag teknik, dan 14 use case yang dilakukan aktor-aktor tersebut.

\section{Activity Diagram}

Activity Diagram menggambarkan berbagai alur aktivitas dalam sistem yang dirancang, bagaimana masing-masing alur berawal, decision yang mungkin berakhir, dan bagaimana mereka berakhir. Activity diagram dapat menggambarkan proses parallel yang mungkin terjadi pada beberapa eksekusi.

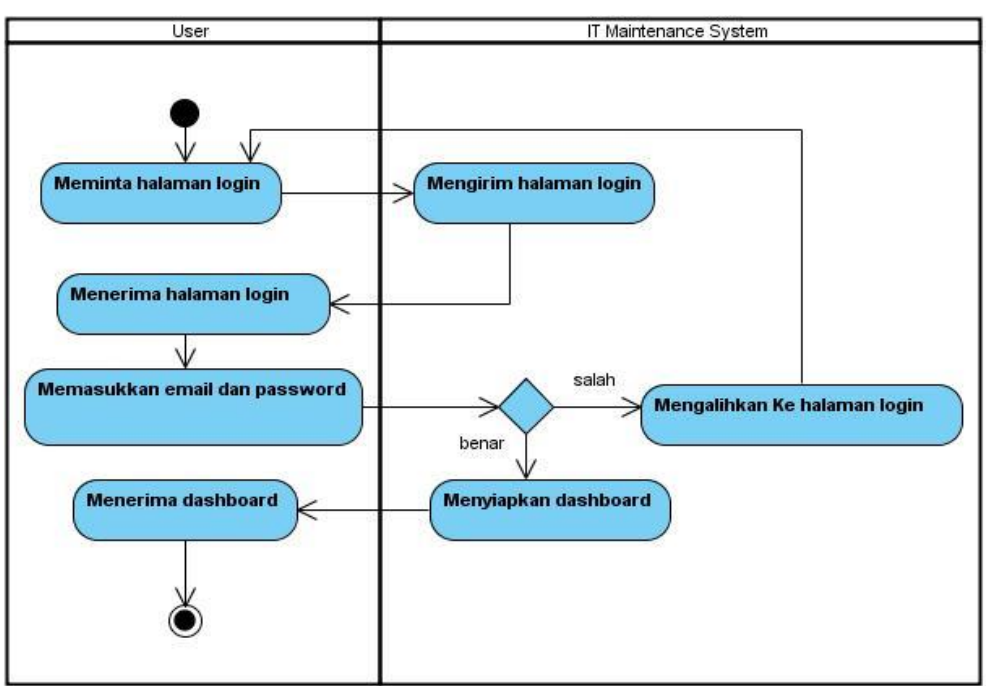

Gambar 2 Activity Diagram Login Sistem Usulan Request Perbaikan

Pada gambar 2 activity diagram, terdapat 7 action yang menggambarkan proses eksekusi permohonan login yang didalamnya terdapat proses verivikasi pada saat memasukkan password dan email.

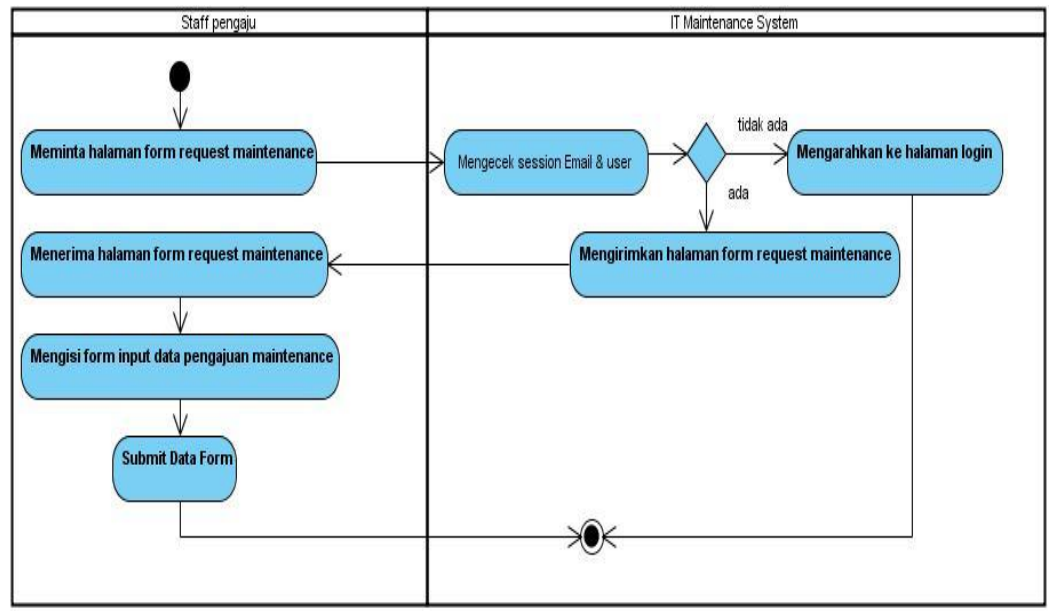

Gambar 3 Diagram Input Form Request Maintenance Sistem Usulan 
Pada gambar 3 activity diagram, terdapat 7 action yang menggambarkan proses eksekusi input permohonan maintenance yang didalamnya terdapat proses verivikasi decision node untuk mengevaluasi dari kondisi sebelumnya.

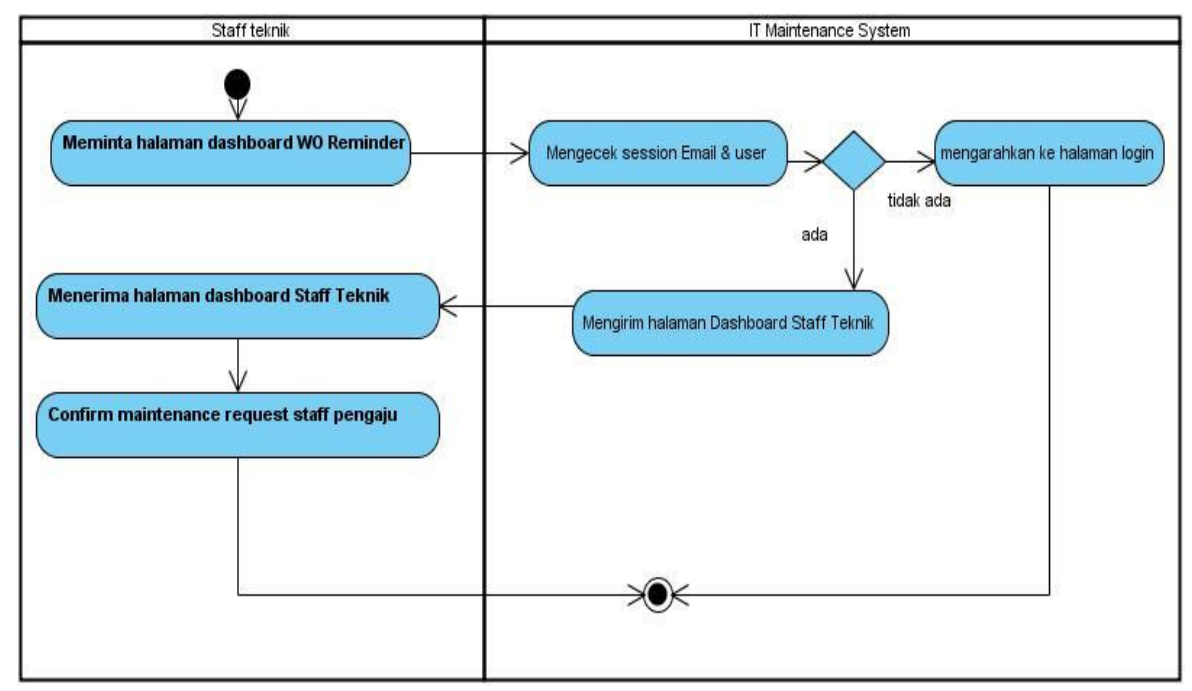

Gambar 4 Activity Diagram Confirm Request Maintenance Sistem Usulan

Pada gambar 4 activity diagram, terdapat 6 action yang menggambarkan proses eksekusi confirm permohonan maintenance yang didalamnya terdapat proses verivikasi decision node untuk mengevaluasi dari kondisi sebelumnya

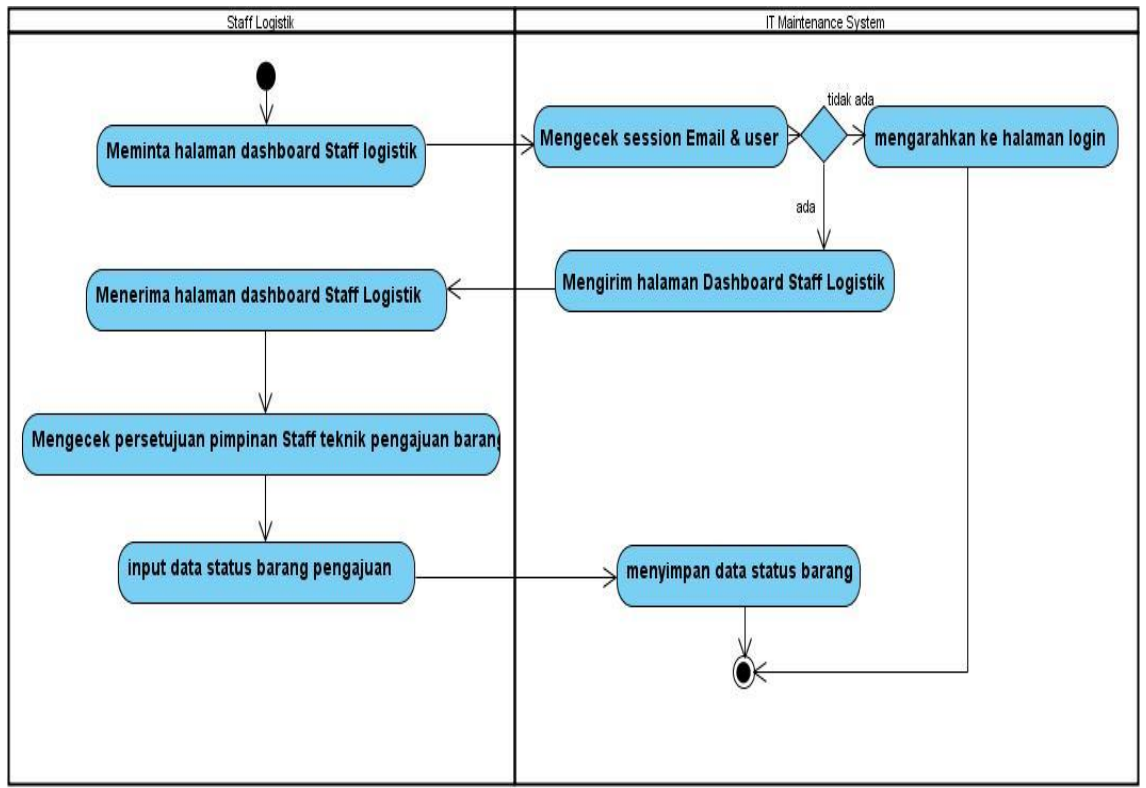

Gambar 5 Activity Diagram Cek dan Input Status Barang Sistem Usulan

Pada gambar 5 activity diagram, terdapat 8 action yang menggambarkan proses eksekusi cek 
dan input status barang yang didalamnya terdapat proses verivikasi decision node untuk mengevaluasi dari kondisi sebelumnya

\section{Class Diagram}

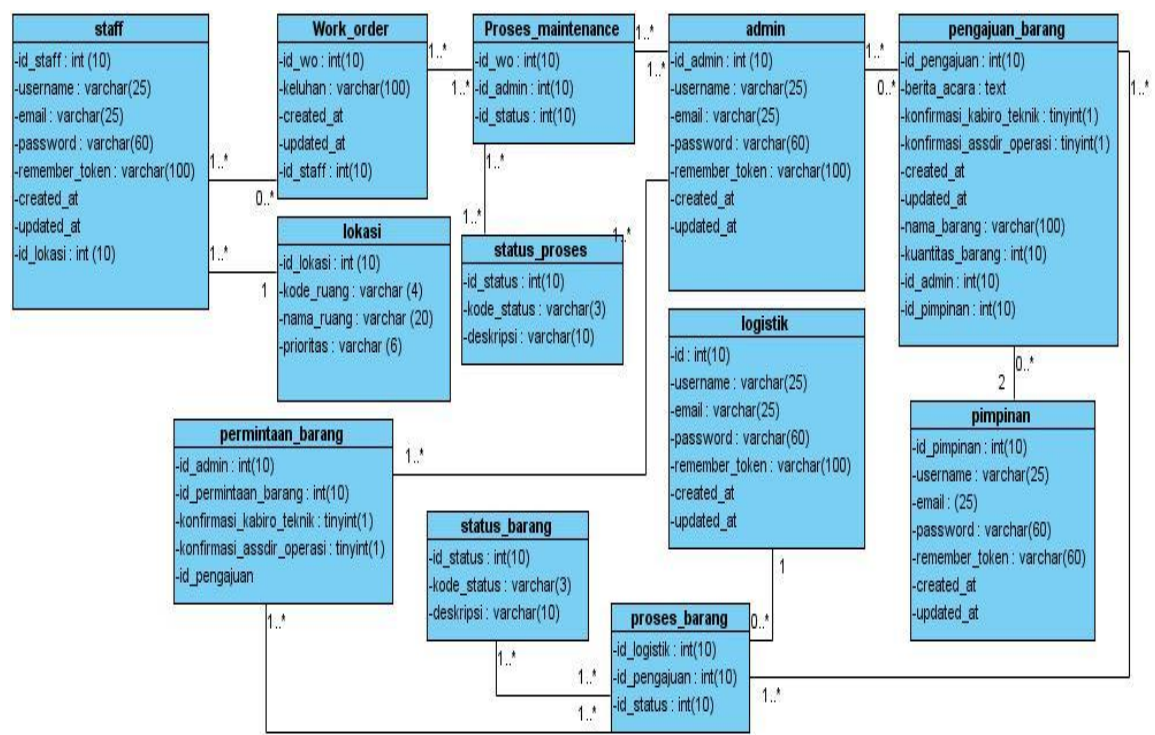

Gambar 6. Class Diagran

Pada gambar 6 diatas class diagram, terdapat 12 class yang merupakan himpunan dari objekobjek yang berbagi atribut serta operasi yang sama dan 12 association yang digunakan untuk memodelkan relasi diantara.

\section{IMPLEMENTASI}

1. Tampilan Menu Staff Login

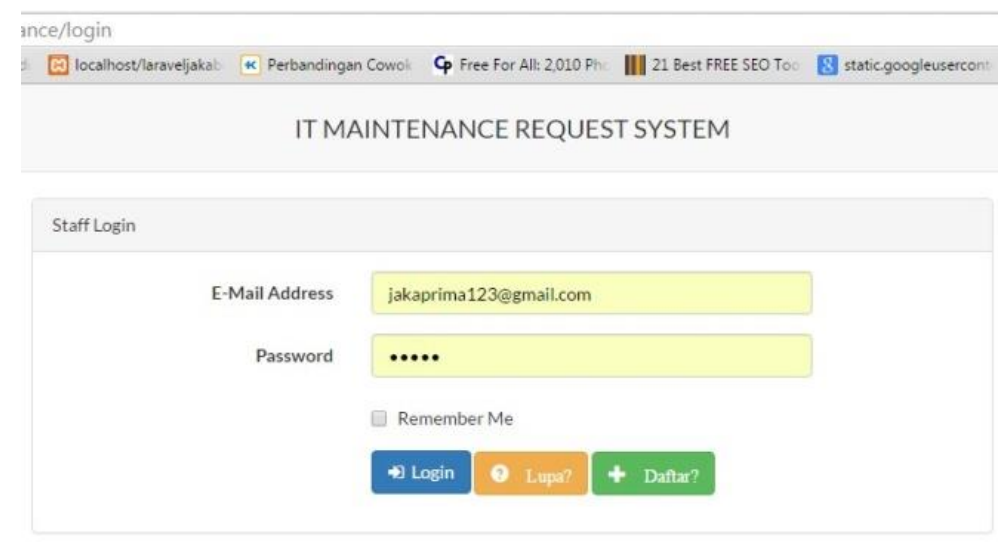

\section{Gambar 7 User Login}

Pada menu ini, disediakan 2 (dua) text box untuk input data login. Dan disediakan juga 3 button trigger untuk proses login, lupa password atau daftar. 
2. Tampilan Menu Dashboard Staff

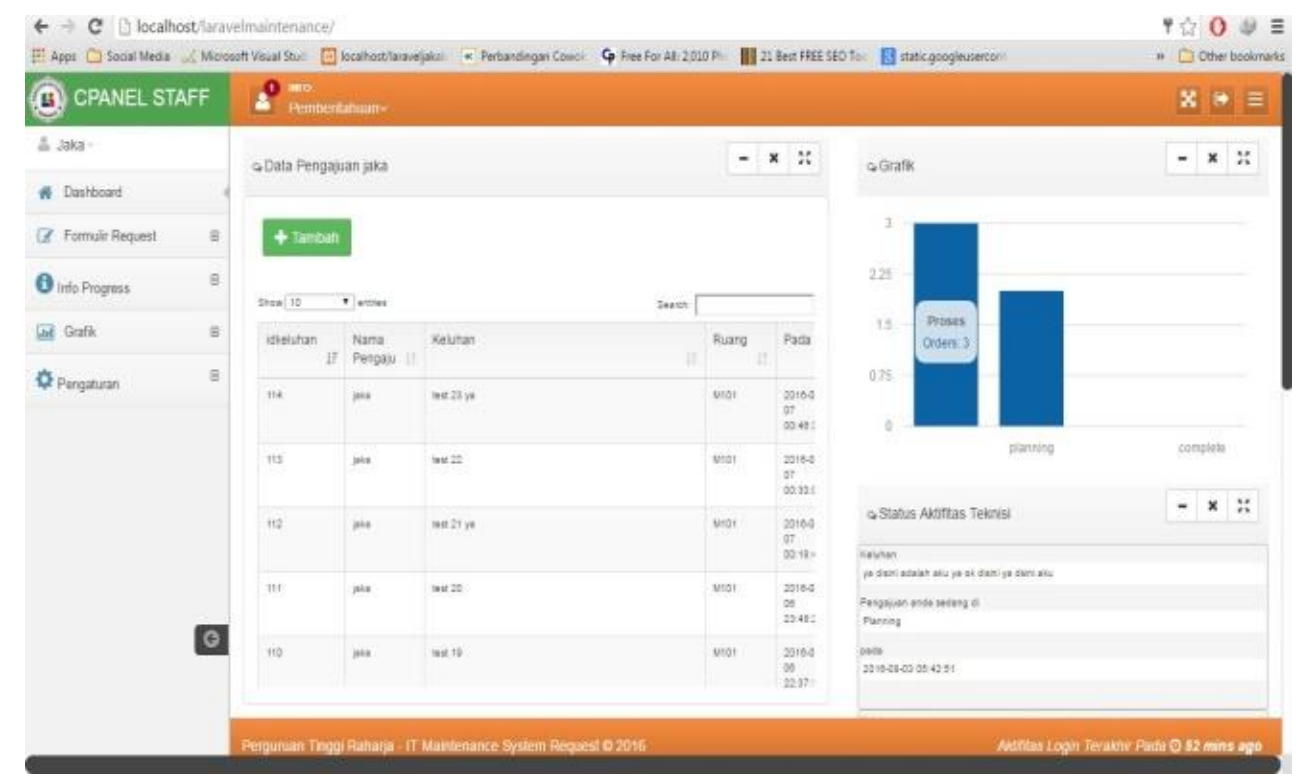

Gambar 9 Dashboard Staff

Pada tampilan ini terdapat menu keseluruhan yang dibutuhkan olah staff, mulai dari : menu form request, menu info progress, info pengguna, grafik, dan pengaturan. Serta difasilitasi dengan menu status aktfitas terkini, sehingga mampu memonitoring dengan baik.

3. Tampilan Menu Keluhan Kerusakan

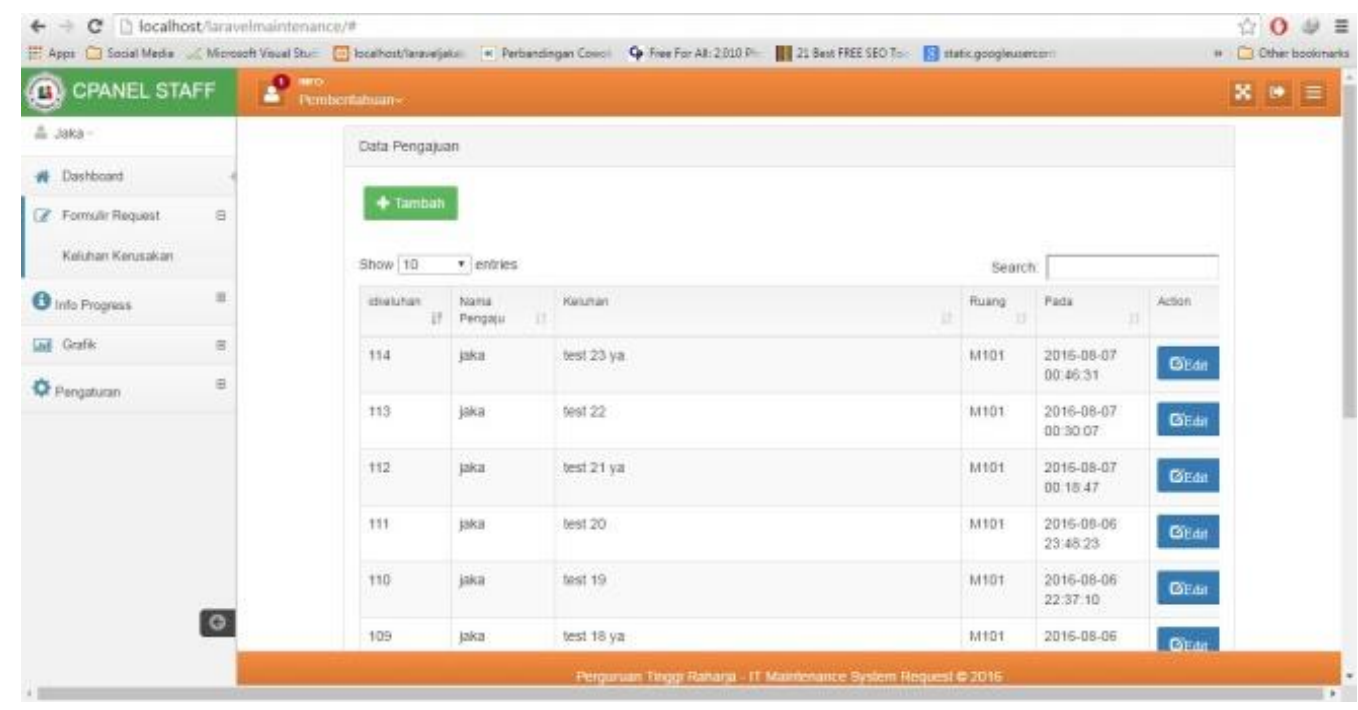

\section{Gambar 10 Keluhan Kerusakan}

Pada menu ini berisikan data pengajuan yang disertai keluhan. Sehingga semua terekam dengan 
baik, mulai dari pencatatan keluhan, ruangan, dan pengguna yang mengajukan keluhan.

4. Tampilan Menu Form Request Keluhan

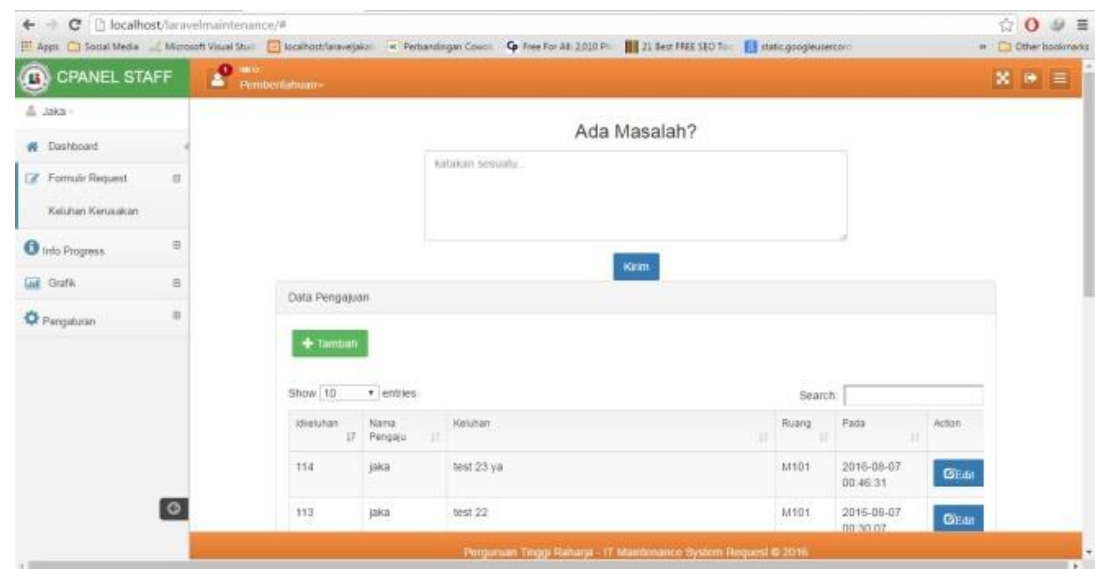

Gambar 11 Form Request Keluhan

Menu form ini sangat memudahkan staf untuk mengisi keluhan yang pada saat itu terjadi. Hanya dengan login dan tuangkan keluhan kedalam text area, lalu bisa langsung di kirim.

5. Tampilan Menu Edit Post

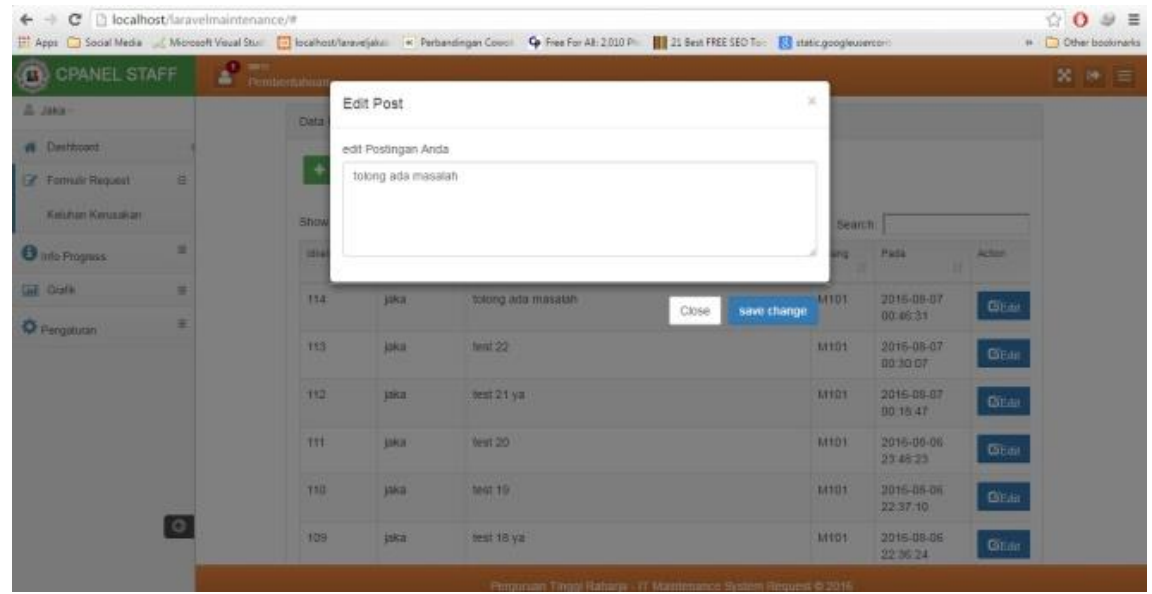

\section{Gambar 5 Edit Post}

Menu ini merupakan lanjutan dari menu form request sebelumnya. Jika ada kesalahan dalam penulisan keluhan, maka bisa di edit kembali. Dan jika sudah maka bisa langsung di klik button trigger "Save Change". 
6. Tampilan Menu Ubah Password User

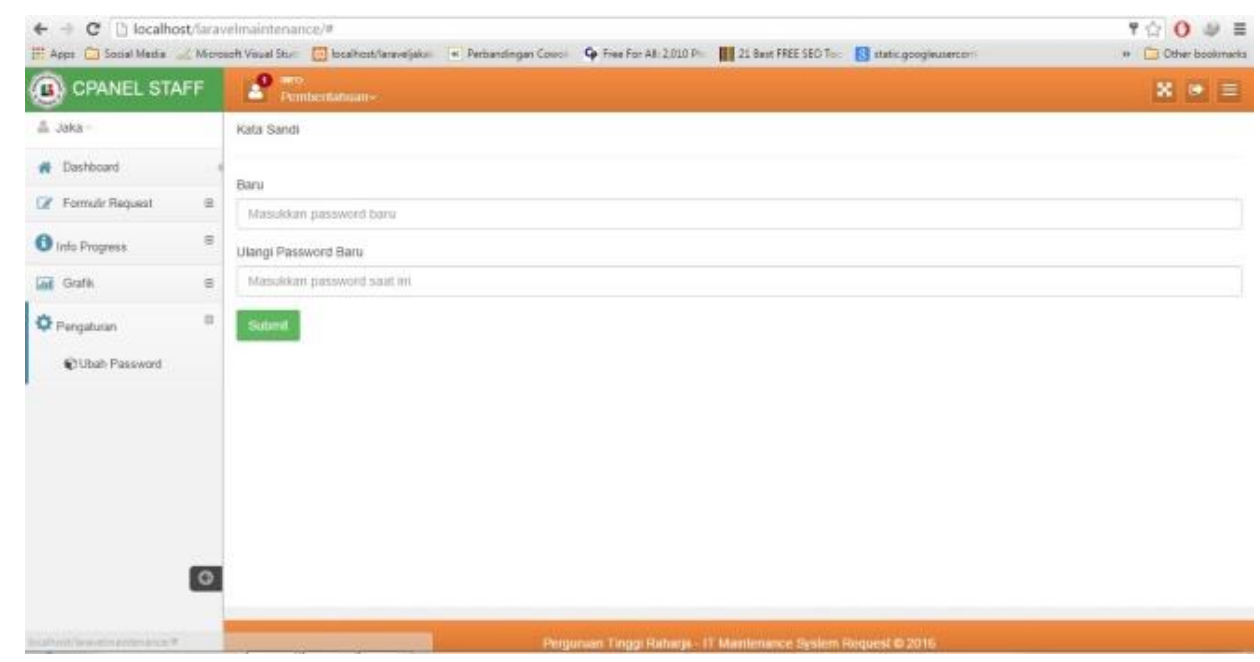

\section{Gambar 6 Ubah Password}

Jika user kurang nyaman dengan password sebelumnya, maka user bisa langusng mengubah password lama dengan yang baru secara mandiri.

7. Tampilan Menu Dashboard Staff Pimpinan

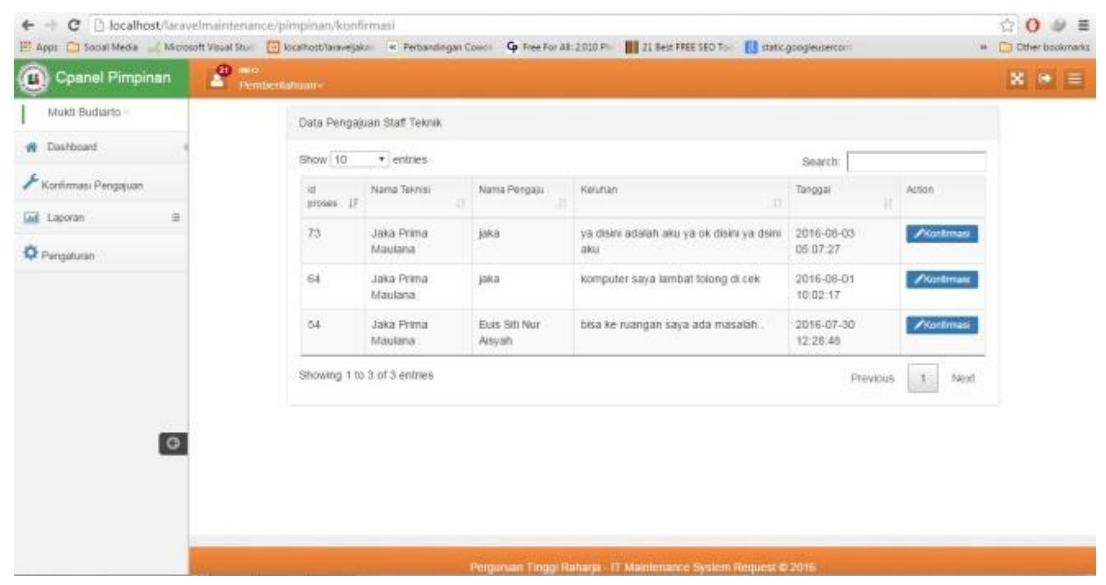

\section{Gambar 7 Dashboard Staff Pimpinan}

Pada menu ini akan menampilkan perbedaan dengan tampilan dashboard staff sebelumnya. Menu ini menampilkan data pengajuan staff teknik yang sudah mengirimkan keluhan kepada pimpinan. 
8. Tampilan Menu Data Pengajuan Yang Akan Di Konfirmasi

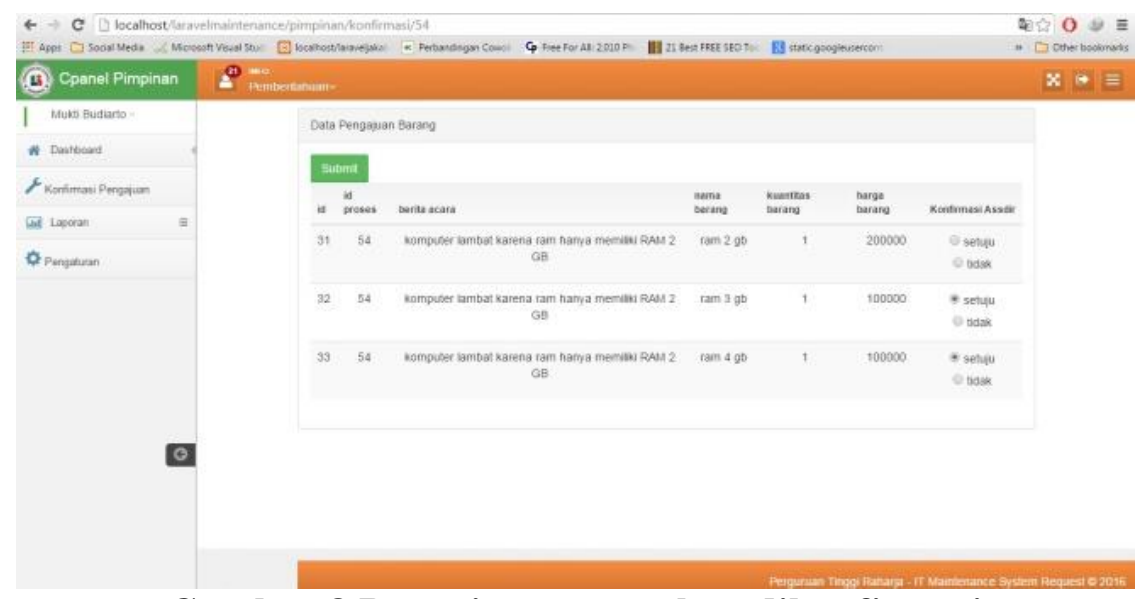

Gambar 8 Pengajuan yang akan dikonfirmasi

Menu konfirmasi pengajuan ini sepenuhnya hanya akan dieksekusi oleh pimpinan. Dalam menu ini pimpinan boleh mengkonfirmasi lebih dari 1 (satu) keluhan.

9. Tampilan Menu Dashboard Teknik

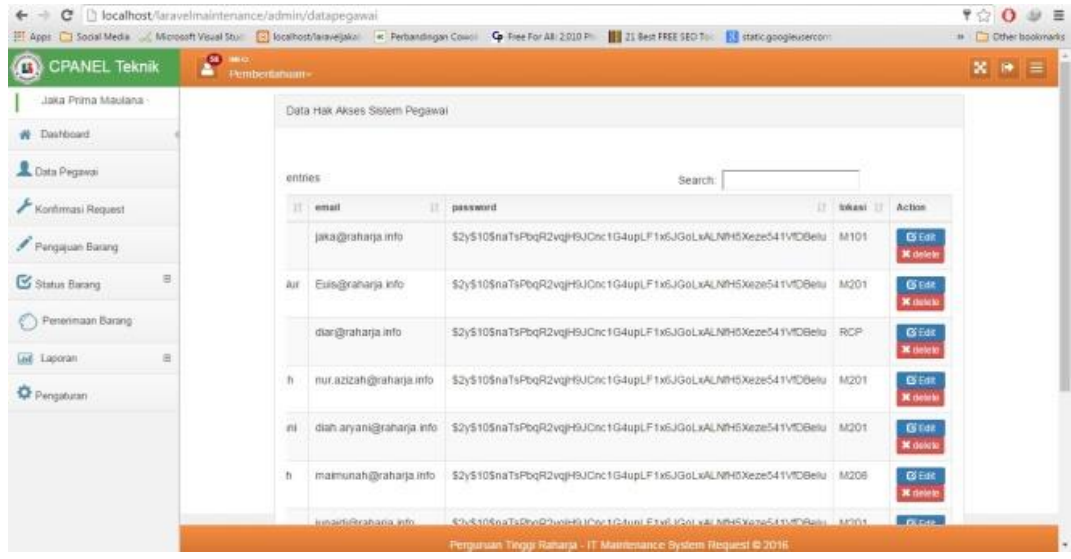

\section{Gambar 9 Dashboard Teknik}

Menu ini menampilkan data hak akses sistem pegawai yang terekam dengan baik, mulai dari email dan password pegawai. Dan kali ini yang bisa mengedit data pegawai sepenuhnya akan dieksekusi oleh staff teknik. 
10. Tampilan Menu Data Keluhan Staff Teknik

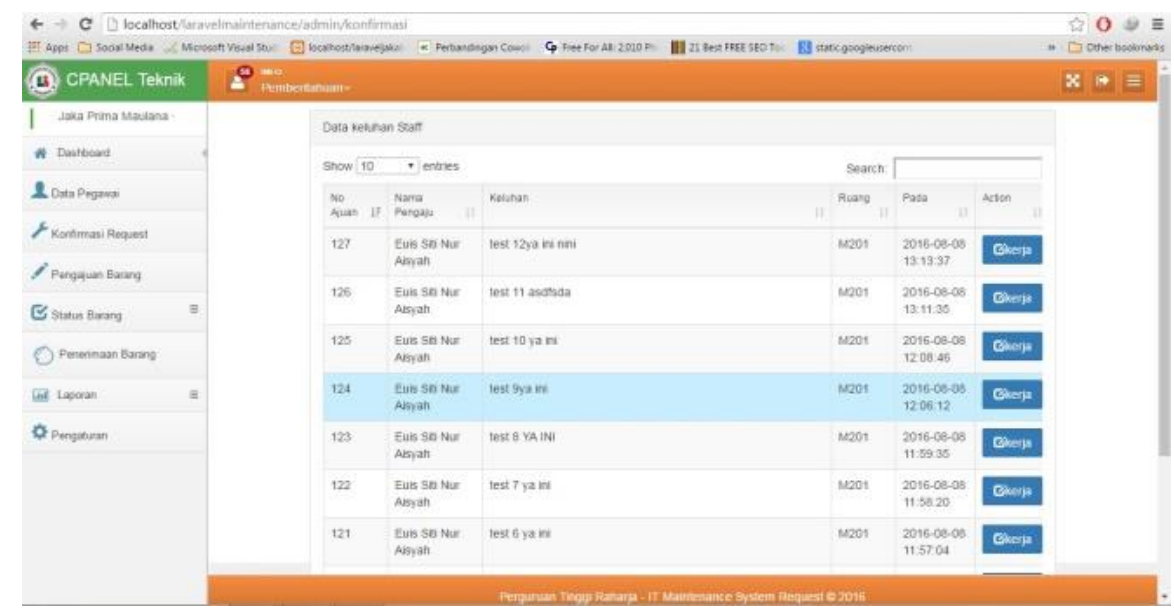

\section{Gambar 10 Data Keluhan Staff}

Pada menu ini, staff mendapatkan kiriman data dari pegawai yang berisikan keluhan-keluhan yang terjadi di masing- masing ruangan. Sehingga staff teknik bisa langsung mengeksekusi keluhan yang terjadi.

11. Tampilan Menu Input Status Proses Pengerjaan

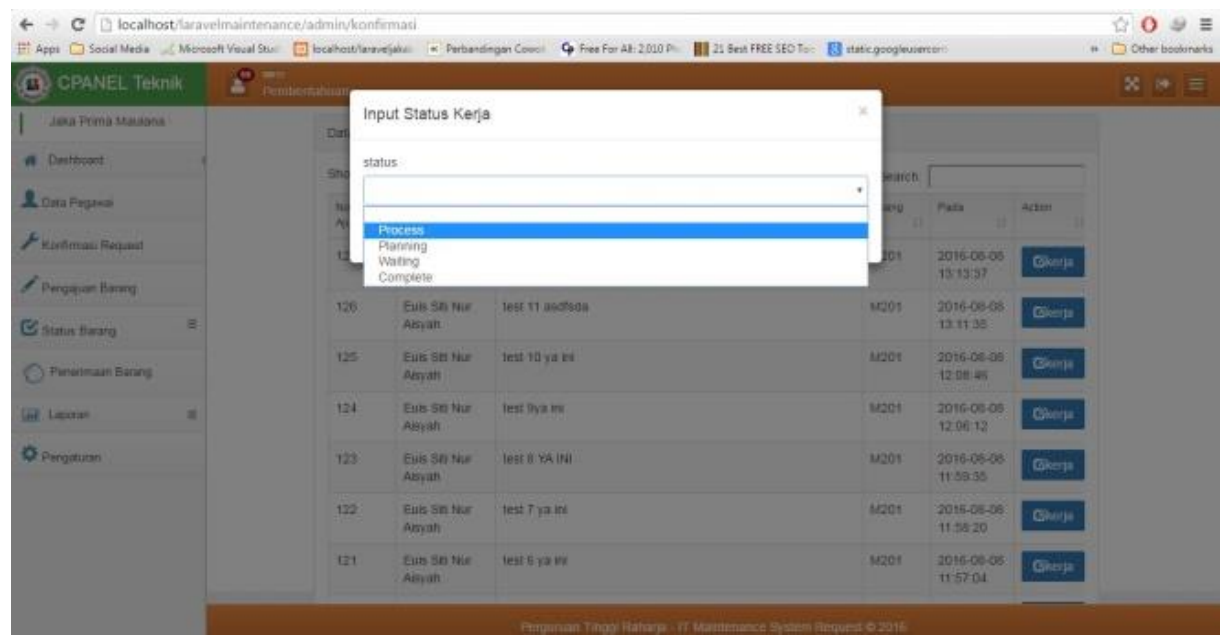

Gambar 11 Input Status Kerja

Pada menu ini, staff teknik bisa memberikan status untuk satu keluhan dengan pilihan : Process, Planning, Waiting, dan Complete. Dengan begitu data keluhan akan memiliki status pengerjaan masing-masing dan sudah pasti semua terekam dengan baik. 
12. Tampilan Menu Data Planning oleh Staff Teknik

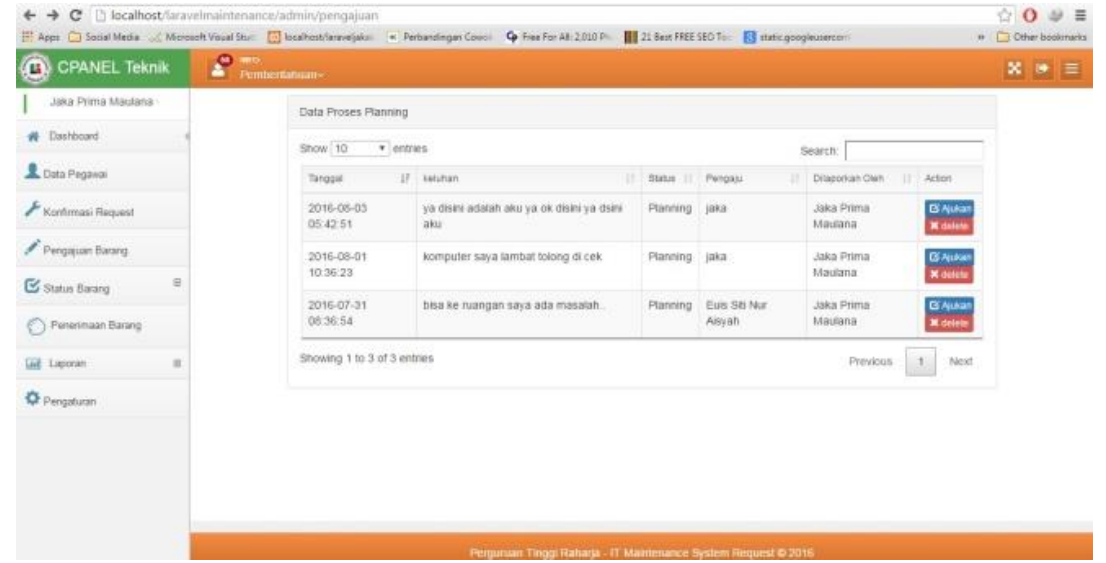

\section{Gambar 12 Data Proses Planning}

Menu ini menampilkan data keluhan beserta statusnya dan staff teknik bisa mengajukan siapa yang akan mengeksekusi keluhan tersebut.

13. Tampilan Menu Pengajuan Barang Kebutuhan oleh Staff Teknik

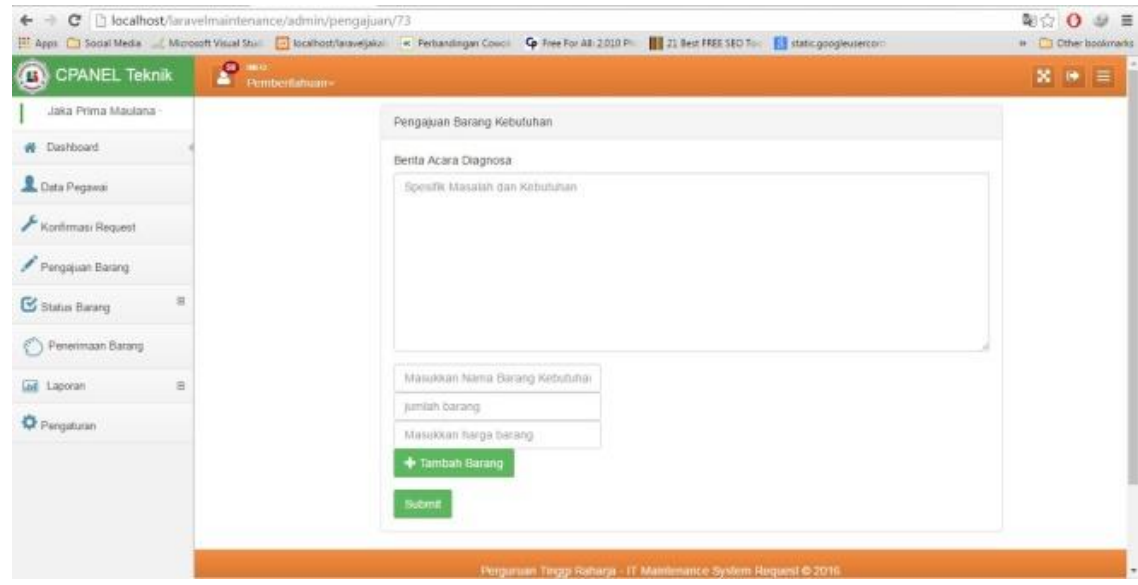

Gambar 13 Pengajuan Barang Kebutuhan

Pada menu ini, staff teknik bisa mengajukan barang sesuai kebutuhan sesuai isi data keluhan. Dengan mengisi form berita acara diagnose. Maka akan langsung dikirimkan kepada pimpinan untuk bisa disetujui atau tidaknya. 
14. Tampilan Menu Data Pengajuan Barang oleh Logistik

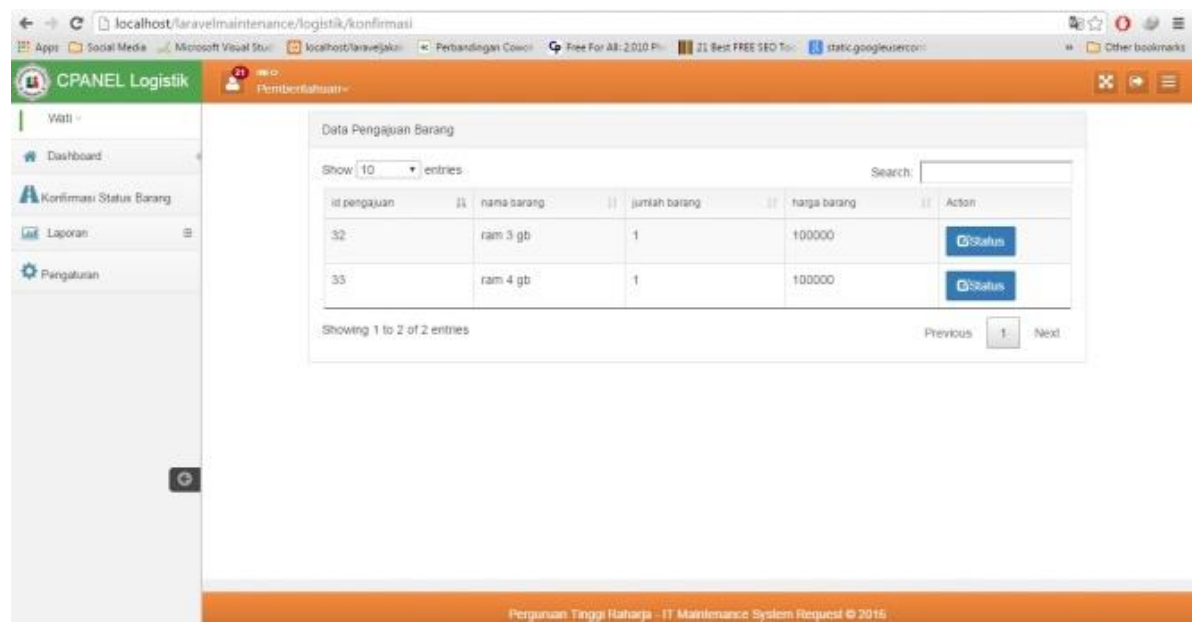

Gambar 14 Data Pengajuan Barang Logistik

Setelah staff teknik mengisi form pengajuan barang kepada pimpinan, dan jika pimpinan sudah menyetujui. Maka logistik akan mengeksekusi semua kebutuhan sesuai request dari pihak staff teknik.

\section{KESIMPULAN}

Dilihat dari sistem berjalan saat ini dirasa masih kurang baik dikarenakan masih manual / masih menggunakan media verbal (lisan) dalam hal permohonan / request maintenance pada computer. System berjalan yang belum dapat mengelola data dengan efektif dan efisien, sehingga dalam menyajikan laporan yang diperlukan masih diperlukan waktu yang cukup lama. Dalam membangun program aplikasi Request Maintenance Teknik Untuk Staff berbasis web yang dibuat menggunakan bahasa pemrograman PHP, yaitu bahasa pemrograman web berbasis server-side, agar dapat menyelesaikan segala bentuk request maintenance perbaikan pada computer dan agar dapat menyelesaikan laporan-laporan yang efektif dan efisien. Dengan adanya program aplikasi SISTEM APLIKASI REQUEST MAINTENANCE TEKNIK berbasis web maka laporan request maintenance yang dihasilkan dapat lebih cepat dan akurat.

\section{DAFTAR PUSTAKA}

[1] Zannuba, Rifqi. 2014. Efek Infrastruktur Sistem Informasi Dan Perbaikan Proses Terhadap Kinerja Waktu Rantai Pasokan. Semarang: Universitas Diponegoro.

[2] Sembiring, Hotmauli. 2012. Perancangan Sistem Informasi Helpdesk pada PT.PINDAD Bandung. Bandung: Universitas Komputer Indonesia.

[3] Ancah, Nugraha. 2011. Aplikasi Helpdesk di CV. Global Mediatama Berbasis Web . Bandung: Universitas Komputer Indonesia.

[4] Nurmaliana, Ana. 2013. Pengembangan Sistem Informasi Campus Service Iduhelp! Pada Perguruan Tinggi Raharja. Tangerang: STMIK Raharja. 
[5] Destianty, Citra. 2014. Pengembangan ROOSTER Dalam Menunjang Sistem Pelayanan iDuHelp! Pada Perguruan Tinggi Raharja. Tangerang: STIMIK Raharja.

[6] Destianty, Citra. 2014. Pengembangan ROOSTER Dalam Menunjang Sistem Pelayanan iDuHelp! Pada Perguruan Tinggi Raharja. Tangerang: STIMIK Raharja. 